\title{
Fault Identification in a Radial Power System Using Fuzzy Logic
}

\author{
Koksal Erenturk ${ }^{1, *}$ and Ismail H. Altas ${ }^{2}$ \\ ${ }^{1}$ Department of Electronic Engineering, Engineering Faculty, Atatürk University, \\ Erzurum, Turkey \\ ${ }^{2}$ Department of Electrical Engineering, Faculty of Engineering \& Architecture, \\ Karadeniz Technical University, Trabzon, Turkey
}

\begin{abstract}
In this study, fuzzy logic is used to identify faults that may occur in a radial power system. In addition to the design concept of fuzzy logic based on protective relay, its architecture and application of the developed prototype system are discussed. A digital relay is designed and tested in a laboratory environment using a developed prototype. In order to constitute a new approach to digital protection purpose, fuzzy logic is used instead of conventional protection approaches. The relay proposed here is developed using conventional relay characteristics by adding some abilities, i.e., to distinguish whether the fault is sub-transient, transient, or permanent, to determine whether the fault is one of the types known as phase-to-phase, phase-to-neutral, double phase-to-neutral, or balanced three phase. Performance analysis is performed and the results obtained are given using graphical illustration to show validity of the proposed relay.
\end{abstract}

Key Words: Fuzzy logic; Digital protective relay; Fault identification; Radial power system.

*Correspondence: Koksal Erenturk, Department of Electronic Engineering, Engineering Faculty, Atatürk University, 25240 Erzurum, Turkey; E-mail: keren@tauni.edu.tr.

641 


\section{INTRODUCTION}

Maintenance and reliability for continued operation are very important problems in power systems. In order to retain continuity of operation, the power outages must be minimized or prevented completely. The power outages are caused mainly by faults that may occur unexpectedly, at any time, anywhere in the power system. Therefore, the faults must be detected very quickly in order to start necessary actions as soon as possible and isolate the faulted parts of the system so that the outages are prevented or minimized. The reliability of a power system is based upon its continuity while in operation. The continuity depends on protective relays which are used to detect faults; they are very important research areas in electrical power systems.

Research in the field of protection and relay techniques for power systems have increased in the past decade. The basis of these techniques is to measure voltage, current, phase angle, frequency, impedance, etc., between fault point and relay position. Substantial research towards better algorithms has been carried out for protective relaying. Fourier transform and adaptive Kalman filtering are some of the various techniques which have been proposed in the literature. ${ }^{[1,2]}$ As a result of increasing application of digital computers and micro-controllers, a new application area has emerged for protective relays. ${ }^{[3-5]}$ Digital relaying algorithms have also been developed, once simulated, and then the results are observed in a personal computer (PC) environment. ${ }^{[6-11]}$ To classify faults, traveling wave relaying is another technique, which is based on the magnetic field constituted by the electrical current. ${ }^{[4,12]}$ To accomplish fast and reliable protective actions using less data, adaptive systems ${ }^{[2,13-16]}$ and expert systems ${ }^{[14,17,18]}$ based protection methods are proposed. Related to these improvements, intelligent protection methods ${ }^{[19-22]}$ are developed. The fuzzy logic based digital protective relay is one of these.

In this study, a digital protective relay has been designed and tested in a laboratory environment using a developed prototype power system model. The digital relay has been accomplished using fuzzy logic instead of conventional digital approaches. This design requires fewer voltage and current readings to detect faults in power systems. First, the voltage and current signals are converted to root mean square (rms) values; then, the type of fault is determined using fuzzy logic, which may be called an "intelligent system."

The relay proposed here is developed using conventional relay characteristics by adding some abilities to distinguish whether the fault is sub-transient, transient, or permanent, to determine whether the fault is one of the types known as phase-to-phase, phase-toneutral, double phase-to-neutral, or balanced three phase. The prototype experimental setup consists of three phases. This prototype system is developed as a radial system and tested for the proposed method. Performance analysis is made and obtained results are given using graphical illustration to show the validity of the proposed relay.

\section{PROTOTYPE POWER SYSTEM MODEL}

The studied system is a radial one, as shown in Fig. 1. The system consists of three phases. Its series impedance and shunt admittance values for each phase are given in Fig. 2. 


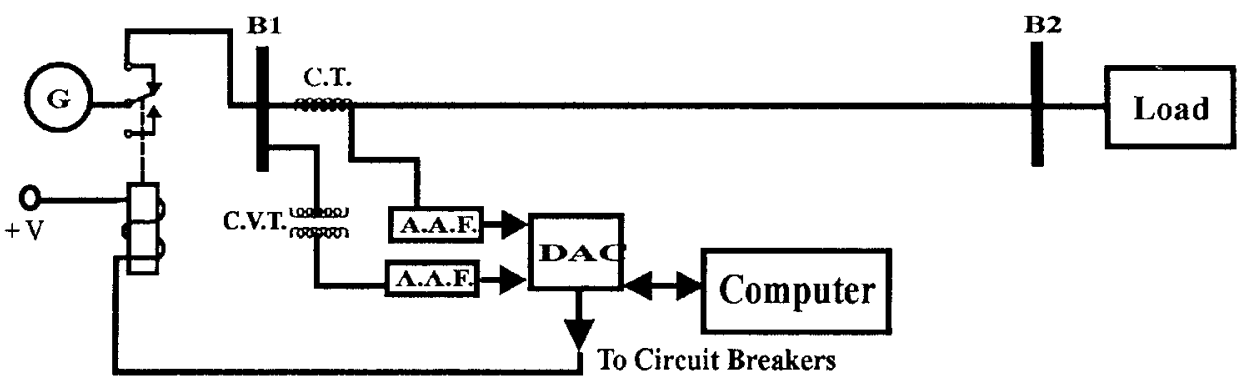

Figure 1. Studied system model.

The transmission line is modeled using a distributed RL equivalent circuit. The type of transmission line model is known as Lily. In Fig. 2, A-B is the input point for power inlet, $\mathrm{C}-\mathrm{D}$ is the output point for power outlet, and between $\mathrm{A}-\mathrm{B}$ and $\mathrm{X}-\mathrm{Y}$ there is an equivalent circuit for each phase. The number of equivalent circuits used is five, which describes $5 \mathrm{~km}$ transmission line length.

As shown in Fig. 3, a data acquisition card (DAC) is used to constitute a connection between the prototype system and the computer. A sampling period is selected, such as $30 \mathrm{kHz}$. To eliminate system noise from both voltage and current samples, an anti-aliasing filter is used per phase.

An IBM PC is used for data acquisition. Its specifications are Pentium $166 \mathrm{MHz}$ processor, $48 \mathrm{MB}$ SDRAM, and $10 \mathrm{~GB}$ HDD. Relay software is written in the Borland Pascal environment; its flow scheme is illustrated in Fig. 4.

For the pre-fault conditions, the following assumptions are considered.

1. The pre-fault conditions are normal steady-state.

2. The source impedances are omitted.

3. The amplitude of sampled current at the bus in which the signals enter is in the range from -0.05 to +0.05 for normal conditions.

To prove validity of the proposed relay, 10 types of faults are considered. Moreover fault impedance and neutral impedance are omitted for all faulted cases.

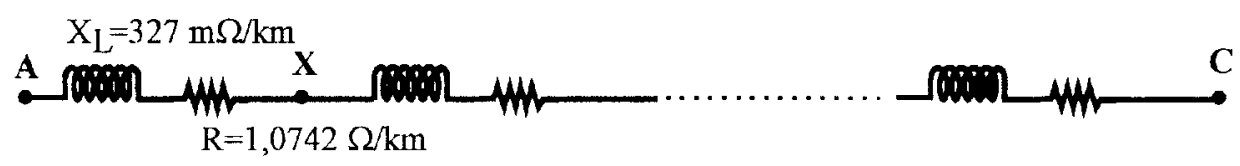

B

Figure 2. Distributed RL equivalent circuit for transmission line. 


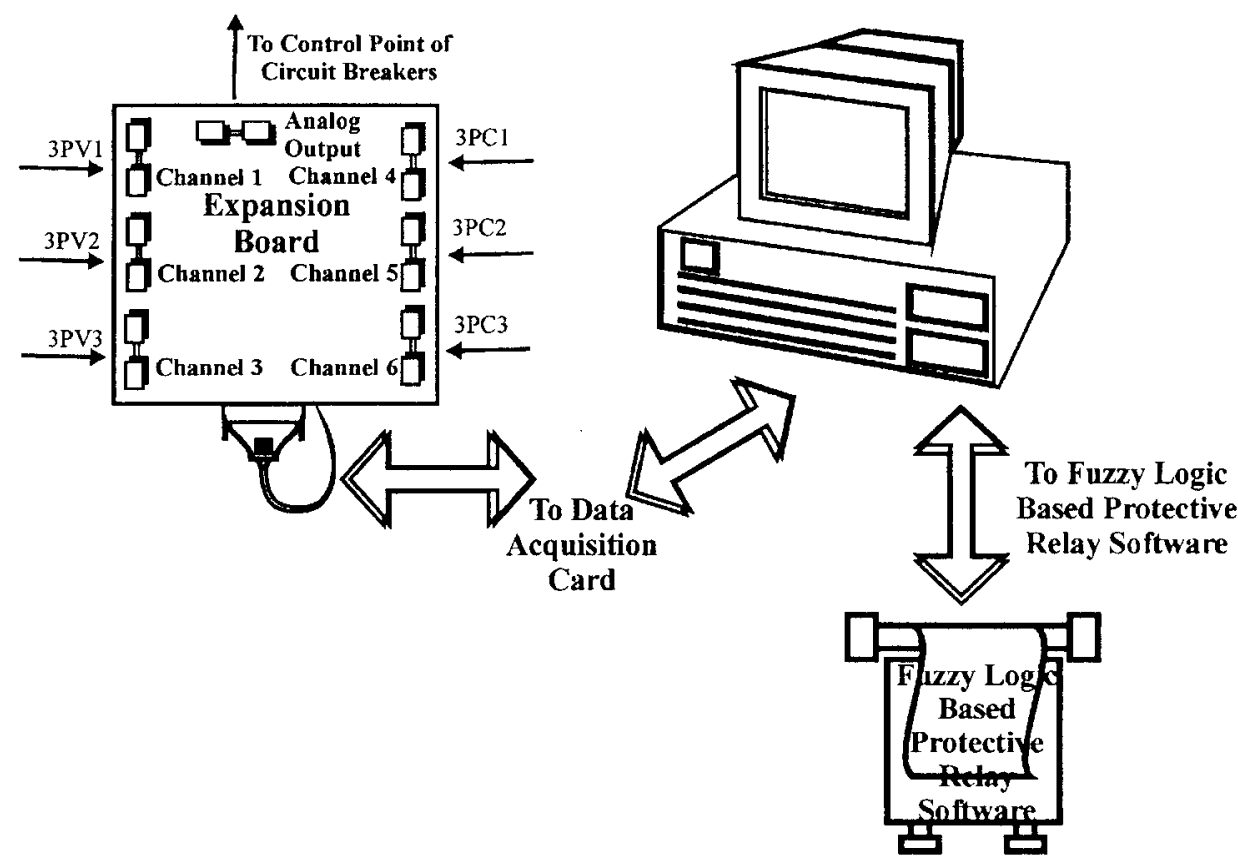

Figure 3. Connection between prototype system and computer.

\section{FAULT IDENTIFICATION USING FUZZY LOGIC}

In this study, fuzzy set theory is used for fault identification purposes. Busbar voltages and line currents are measured from the prototype system; they are used to describe the state of the system. In this context, only the current values at the transmission line are used, for simplicity, and to reduce the data requirement. For the radial system studied here, 10 types of faults are to be classified by the fuzzy logic based protective relay (FLBPR).

As expressed in Eqs. 1-4, the rms values of the phase currents and their sums were utilized as inputs for the FLBPR. In order to distinguish the neutral based faults from the others, the sum of the rms values of the phase currents is used.

$$
\begin{aligned}
I_{\mathrm{a}_{\mathrm{rms}}} & =\sqrt{\frac{1}{T} \int_{0}^{T}\left(i_{\mathrm{a}}(t)\right)^{2} \mathrm{~d} t} \\
I_{\mathrm{b}_{\mathrm{rms}}} & =\sqrt{\frac{1}{T} \int_{0}^{T}\left(i_{\mathrm{b}}(t)\right)^{2} \mathrm{~d} t} \\
I_{\mathrm{c}_{\mathrm{rms}}} & =\sqrt{\frac{1}{T} \int_{0}^{T}\left(i_{\mathrm{c}}(t)\right)^{2} \mathrm{~d} t} \\
I_{\mathrm{sum}} & =I_{\mathrm{a}_{\mathrm{rms}}}+I_{\mathrm{b}_{\mathrm{rms}}}+I_{\mathrm{c}_{\mathrm{rms}}}
\end{aligned}
$$




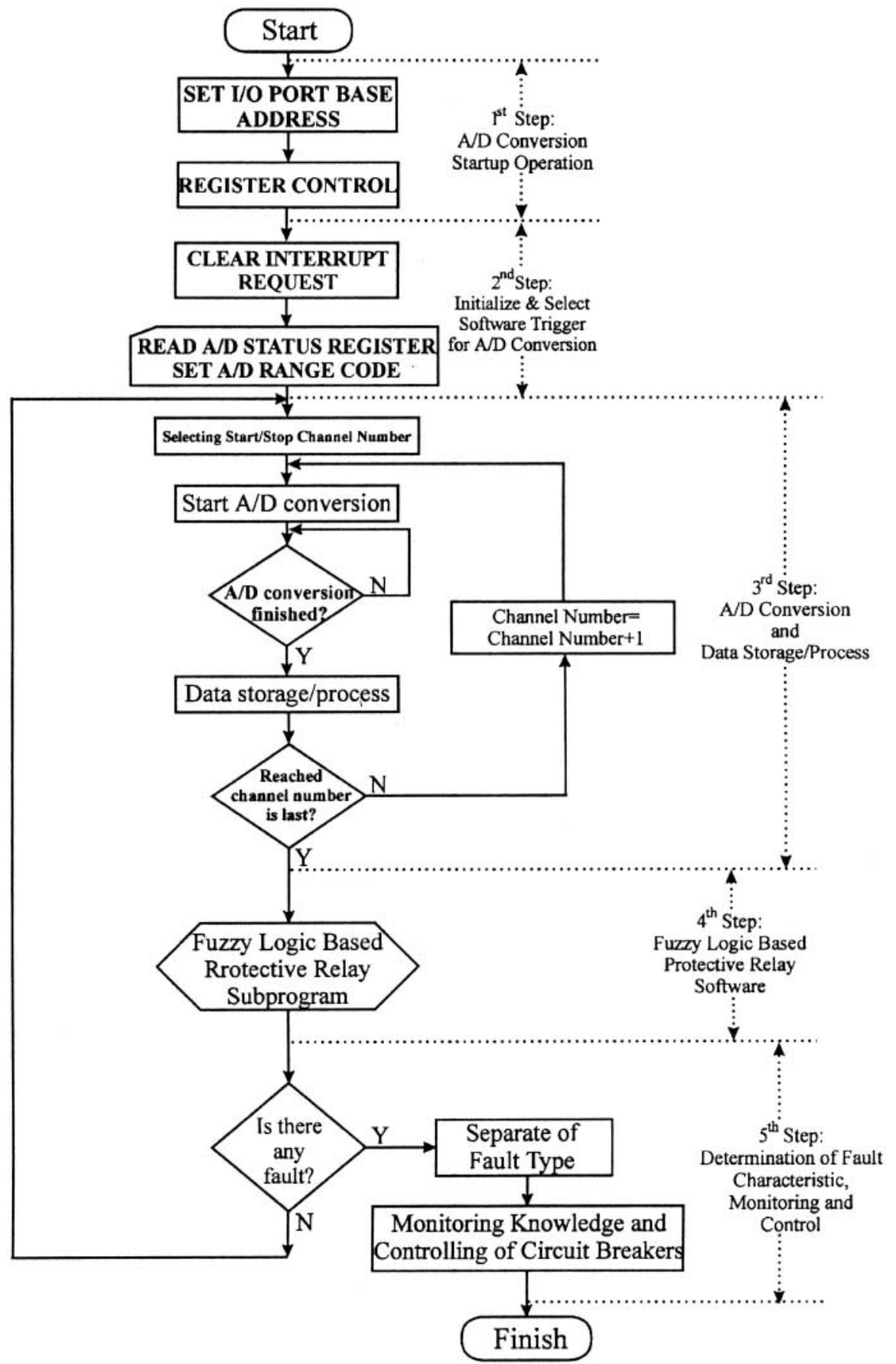

Figure 4. Flow scheme for intelligent relay algorithm. 
As shown in Fig. 4, the intelligent relay algorithm is based on fuzzy logic. The FLBPR has three steps as shown in Fig. 5. These are as follows.

1. Fuzzification (converting crisp values into fuzzy values).

2. Inference mechanism (rule base and If-Then rules).

3. Defuzzification (converting fuzzy values into crisp values).

Trapezoidal membership functions are used for fuzzification of rms values of the phase currents and their sums. Graphical illustration of these membership functions and their ranges are shown in Fig. 6.

Membership functions, which are drawn in Fig. 6(a) are used for fuzzification of all rms values of phase currents. The sums of the rms values of phase currents are also converted into fuzzy values using membership functions shown in Fig. 6(b). This conversion process is the first step of the FLBPR.

As shown in Fig. 2, the total impedance value of per length is $1.0742+$ $0.327=1.4012 \Omega$. A transformer that has a $220: 24$ conversion ratio is used to obtain power supply per phase. Similar to power supply, in order to transfer current values to the computer in a suitable form, a transformer which has $220: 24$ conversion ratio, is used. Current values are obtained from a resistance as shown in Fig. 7. The reason for the use of this resistance is to obtain the value of the current which flows through the line, as a voltage value. As can be seen from Fig. 7(a), it is obvious that, for a single phase-neutral fault, the value of the fault current, $i$, that flows through from live contact to neutral connection can be expressed as:

$$
i=\frac{V_{\mathrm{a}}}{R_{i}+k Z_{\mathrm{L}}}
$$

where $V_{\mathrm{a}}$ is the power supply voltage, $R_{i}$ is resistance value used for current sampling, $k$ is number of equivalent circuit, and $Z_{\mathrm{L}}$ is the line impedance per kilometer length. If $k$ is assumed to be equal to 1 , then $i_{\text {rms }}$ can be found to be equal to $1.35 \mathrm{~A}$; this is the maximum value for the membership function, which is labeled as CS (Closure to Zero).

\section{Fuzzy Processor}

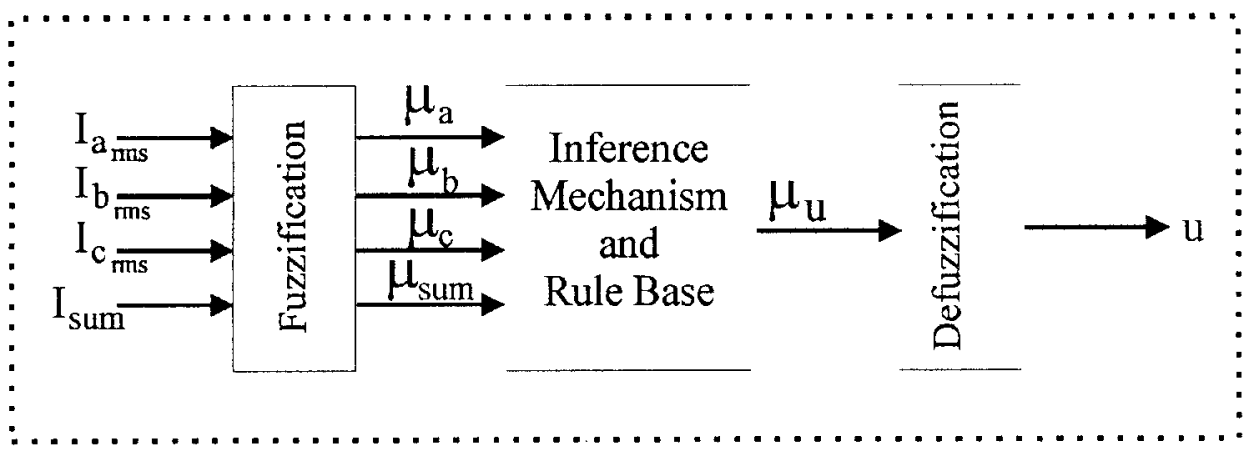

Figure 5. Fuzzy processor and input-output units. 

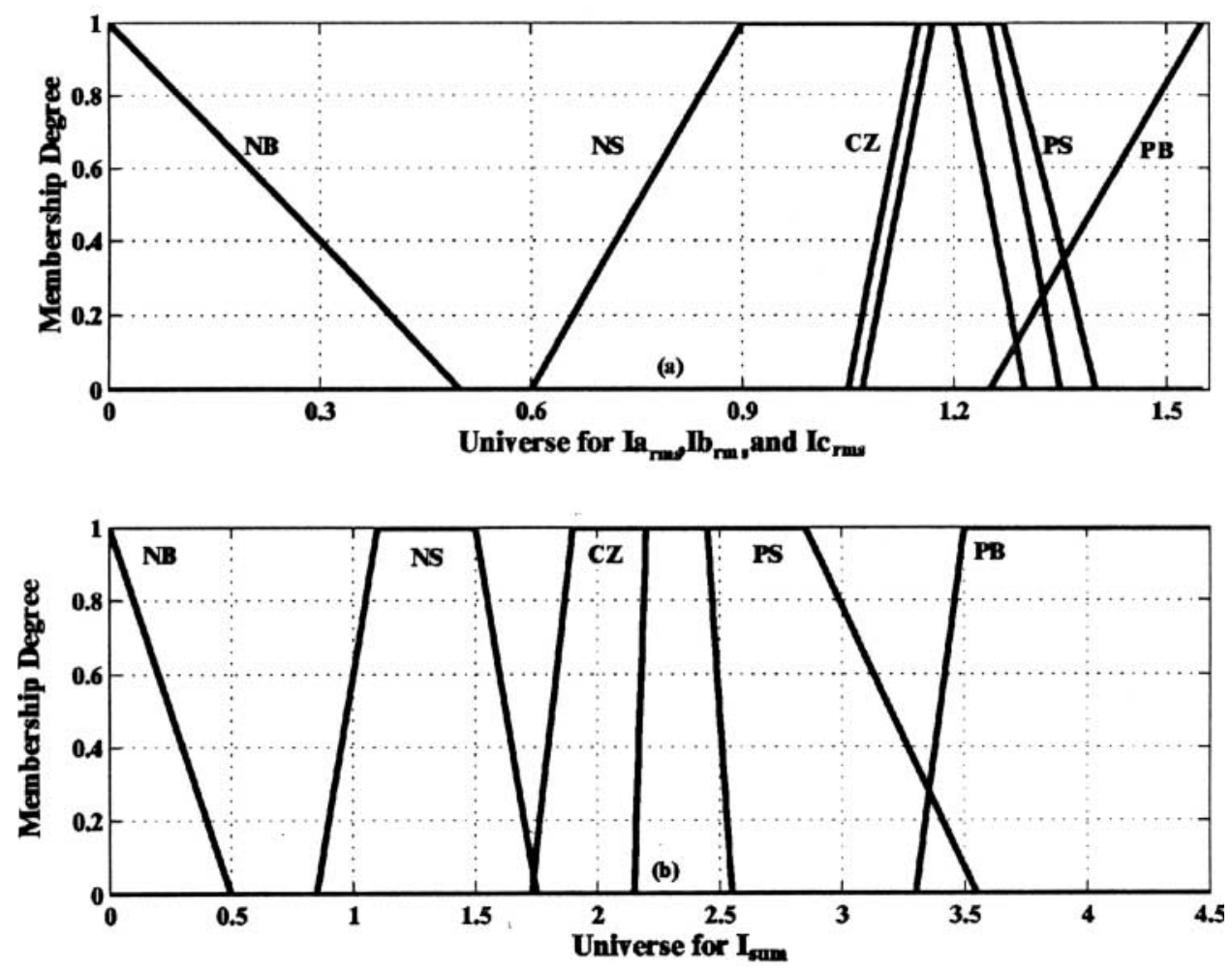

Figure 6. Used membership functions for fuzzification process.

Similarly, if $k$ is assumed to be equal to 5 , then $i_{\text {rms }}$ can be found to be equal to $1.05 \mathrm{~A}$; this is the minimum value for CS (Closure to Zero). The value of $i_{\mathrm{rms}}$ is $i / \sqrt{ } 2$. For consideration of double line fault, as shown in Fig. 7(b), maximum and minimum values are found as equal to 1.3 and $0.6 \mathrm{~A}$, respectively. These values are used to define range of NS (Negative Small) labeled membership function. Mathematical expression of these calculations can be given as:

$$
i=\frac{V_{\mathrm{a}}}{2\left(R_{i}+k Z_{\mathrm{L}}\right)}
$$

Current values, which are transferred to the computer, are measured values that are given in Eqs. (5) and (6). Zero-crossing software is used to determine the period of the current. Using this software, the rms value of the current is calculated and then applied to FLBPR software. Definition of the ranges of other membership functions is similar to above-mentioned method and same consideration is given. Separation of the universe for $I_{\text {sum }}$ is based on Eq. (4). Ranges of the membership functions belong to $I_{\text {sum }}$ can be calculated using Eq. (4), simply. For instance, if $I_{\mathrm{a}_{\mathrm{rms}}}$ and $I_{\mathrm{b}_{\mathrm{rms}}}$ are equal to $1 \mathrm{~A}$ then, from Eq. (4) $I_{\text {sum }}$ will be equal to $2.05 \mathrm{~A}$. This value describes the double line fault case between the $\mathrm{A}$ and $\mathrm{B}$ phases. 
Equivalent Circuit For Single Phase Neutral Fault

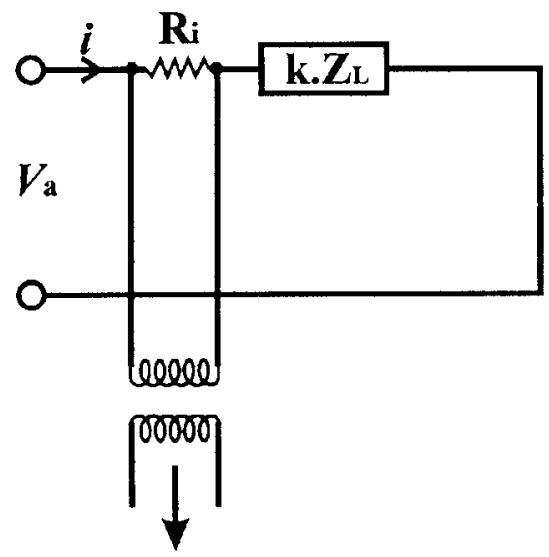

To DAC

(a)
Equivalent Circuit For Double Phase Fault

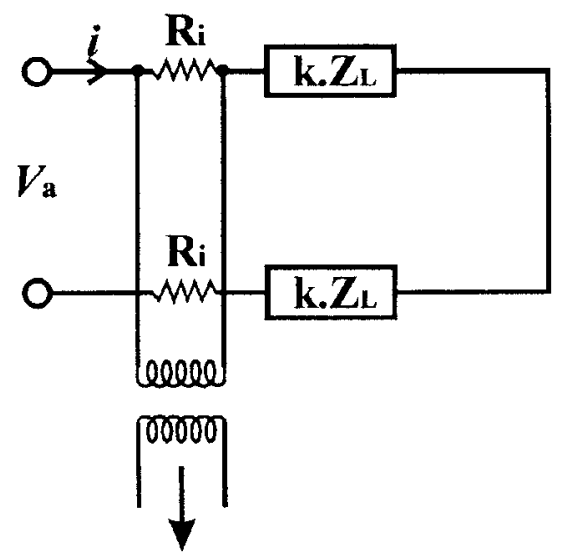

To DAC

(b)

Figure 7. Equivalent circuits for tuning membership functions.

Membership degrees of input values are determined with the assistance of the membership functions, as shown in Fig. 6. These membership degrees are applied to the rule base that has 11 "If-Then" type rules. This mechanism is the inference mechanism, which is the second step of the FLBPR, given as follows.

If $I_{\mathrm{a}_{\mathrm{rms}}}=\mathrm{NB}$ and $I_{\mathrm{b}_{\mathrm{rms}}}=\mathrm{NB}$ and $I_{\mathrm{c}_{\mathrm{rms}}}=\mathrm{NB}$ and $I_{\mathrm{sum}}=\mathrm{NB}$ then $u=1$ (No Fault)

If $I_{\mathrm{a}_{\mathrm{rms}}}=\mathrm{CZ}$ and $I_{\mathrm{b}_{\mathrm{rms}}}=\mathrm{NB}$ and $I_{\mathrm{c}_{\mathrm{rms}}}=\mathrm{NB}$ and $I_{\text {sum }}=\mathrm{NS}$ then $u=1000$ (A Phase to Neutral Fault)

If $I_{\mathrm{a}_{\mathrm{rms}}}=\mathrm{NB}$ and $I_{\mathrm{b}_{\mathrm{rms}}}=\mathrm{CZ}$ and $I_{\mathrm{c}_{\mathrm{rms}}}=\mathrm{NB}$ and $I_{\text {sum }}=\mathrm{NS}$ then $u=2000$ (B Phase to Neutral Fault)

If $I_{\mathrm{a}_{\mathrm{rms}}}=\mathrm{NB}$ and $I_{\mathrm{b}_{\mathrm{rms}}}=\mathrm{NB}$ and $I_{\mathrm{c}_{\mathrm{rms}}}=\mathrm{CZ}$ and $I_{\text {sum }}=\mathrm{NS}$ then $u=3000$ (C Phase to Neutral Fault)

If $I_{\mathrm{a}_{\mathrm{rms}}}=\mathrm{NS}$ and $I_{\mathrm{b}_{\mathrm{rms}}}=\mathrm{NS}$ and $I_{\mathrm{c}_{\mathrm{rms}}}=\mathrm{NB}$ and $I_{\mathrm{sum}}=\mathrm{CZ}$ then $u=4000(\mathrm{~A}-\mathrm{B}$ Phase to Phase Fault)

If $I_{\mathrm{a}_{\mathrm{rms}}}=\mathrm{NS}$ and $I_{\mathrm{b}_{\mathrm{rms}}}=\mathrm{NB}$ and $I_{\mathrm{c}_{\mathrm{rms}}}=\mathrm{NS}$ and $I_{\text {sum }}=\mathrm{CZ}$ then $u=5000(\mathrm{~A}-\mathrm{C}$ Phase to Phase Fault)

If $I_{\mathrm{a}_{\mathrm{rms}}}=\mathrm{NB}$ and $I_{\mathrm{b}_{\mathrm{rms}}}=\mathrm{NS}$ and $I_{\mathrm{c}_{\mathrm{rms}}}=\mathrm{NS}$ and $I_{\mathrm{sum}}=\mathrm{CZ}$ then $u=6000(\mathrm{~B}-\mathrm{C}$ Phase to Phase Fault)

If $I_{\mathrm{a}_{\mathrm{rms}}}=\mathrm{PS}$ and $I_{\mathrm{b}_{\mathrm{rms}}}=\mathrm{PS}$ and $I_{\mathrm{c}_{\mathrm{rms}}}=\mathrm{NB}$ and $I_{\text {sum }}=\mathrm{PS}$ then $u=7000(\mathrm{~A}-\mathrm{B}-\mathrm{N}$ Double Phase to Neutral Fault) 
If $I_{\mathrm{a}_{\mathrm{rms}}}=\mathrm{PS}$ and $I_{\mathrm{b}_{\mathrm{rms}}}=\mathrm{NB}$ and $I_{\mathrm{c}_{\mathrm{rms}}}=\mathrm{PS}$ and $I_{\mathrm{sum}}=\mathrm{PS}$ then $u=8000(\mathrm{~A}-\mathrm{C}-\mathrm{N}$ Double Phase to Neutral Fault)

If $I_{\mathrm{a}_{\mathrm{rms}}}=\mathrm{NB}$ and $I_{\mathrm{b}_{\mathrm{rms}}}=$ PS and $I_{\mathrm{c}_{\mathrm{rms}}}=$ PS and $I_{\text {sum }}=$ PS then $u=9000(\mathrm{~B}-\mathrm{C}-\mathrm{N}$ Double Phase to Neutral Fault)

If $I_{\mathrm{a}_{\mathrm{rms}}}=\mathrm{PB}$ and $I_{\mathrm{b}_{\mathrm{rms}}}=\mathrm{PB}$ and $I_{\mathrm{c}_{\mathrm{rms}}}=\mathrm{PB}$ and $I_{\text {sum }}=\mathrm{PB}$ then $u=25000$ (Balanced Three Phase Fault)

These two steps can be summarized as shown in Fig. 8. As a third step, results obtained from overall rules are entered into the defuzzification process. To convert fuzzy values into crisp values a center of area (COA) method, proposed by Mamdani, is used. This method can be expressed as:

$$
u_{\mathrm{COA}}=\frac{\sum_{i} \mu_{i}(u) \mathrm{d} u}{\sum_{i} \mu_{i}(u)}
$$

In terms of the different fault types, different outputs are obtained from the FLBPR. Using FLBPR, faulted phase or phases are also determined. To distinguish whether the fault is sub-transient, transient, or permanent, synchronous machine characteristics are used. ${ }^{[23]}$ For this purpose, for sub-transient period and transient period, 2 and 30 periods are used, respectively. After 30 periods, characteristics of the fault are recognized as permanent.

\section{RESULTS}

To illustrate the above discussion, phase current curves and outputs of the FLBPR for different fault types are shown in Figs. 9-12.

As can be seen from Fig. 9, there is no change for current curves of other phases, except faulty phase, which is a single line to neutral fault. Output of the FLBPR is as in the defined rule base. For instance, the output of the FLBPR is increased from 1 to 1000 for a short-circuit instant between phase A and neutral. If there is no fault, the

\section{If $\mathrm{I}_{\mathrm{rms}}=\mathrm{NB}$ and $\mathrm{Ib}_{\mathrm{r}}=\mathrm{mi}$ CZ and $\mathrm{Ic}=\mathrm{m} \mathrm{NB}$ and $\mathrm{I}_{\text {sum }}=\mathrm{NS}$ then $\mathrm{u}=2000$} (B Phase To Neutral Fault)

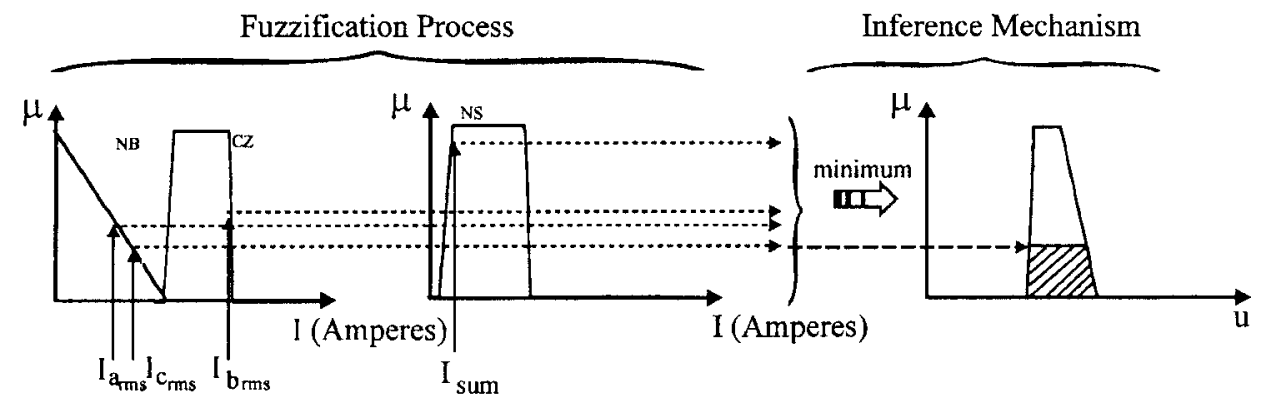

Figure 8. Fuzzification and inference mechanism. 


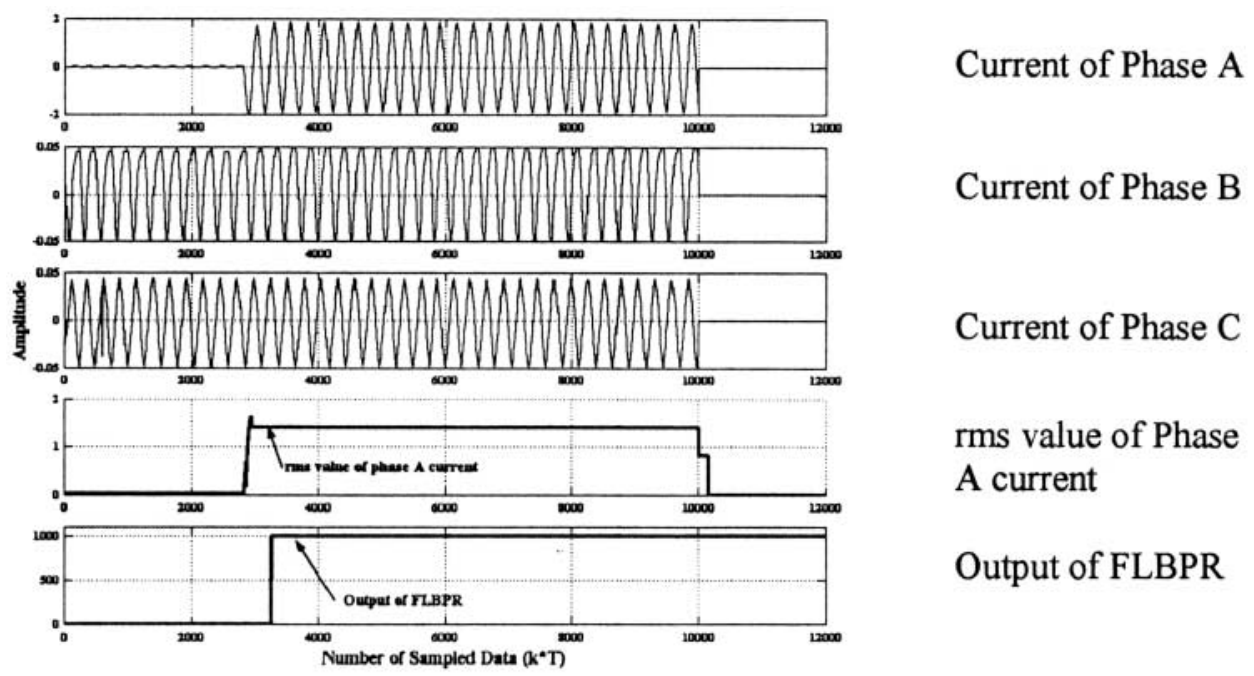

Figure 9. Single phase-neutral fault and output of intelligent relay.

output of the FLBPR is equal to 1. Similarly, output of the FLBPR is equal to 2000 and 3000 for B phase to neutral, and C phase to neutral faults, respectively. Until the time reach to 30 periods, the operator is alerted with a warning sound. After the 30 periods, the relay contacts are energized and the power inlet of the system is closed.

The sum of the rms values of the phase current is used for distinguishing neutral based faults from others. As shown in Figs. 10 and 11, and defined in the rule base, the FLBPR has no dependency to the mathematical model. For this reason, distinguishing these faults is simple. Similar to single line to neutral fault, the output of the FLBPR

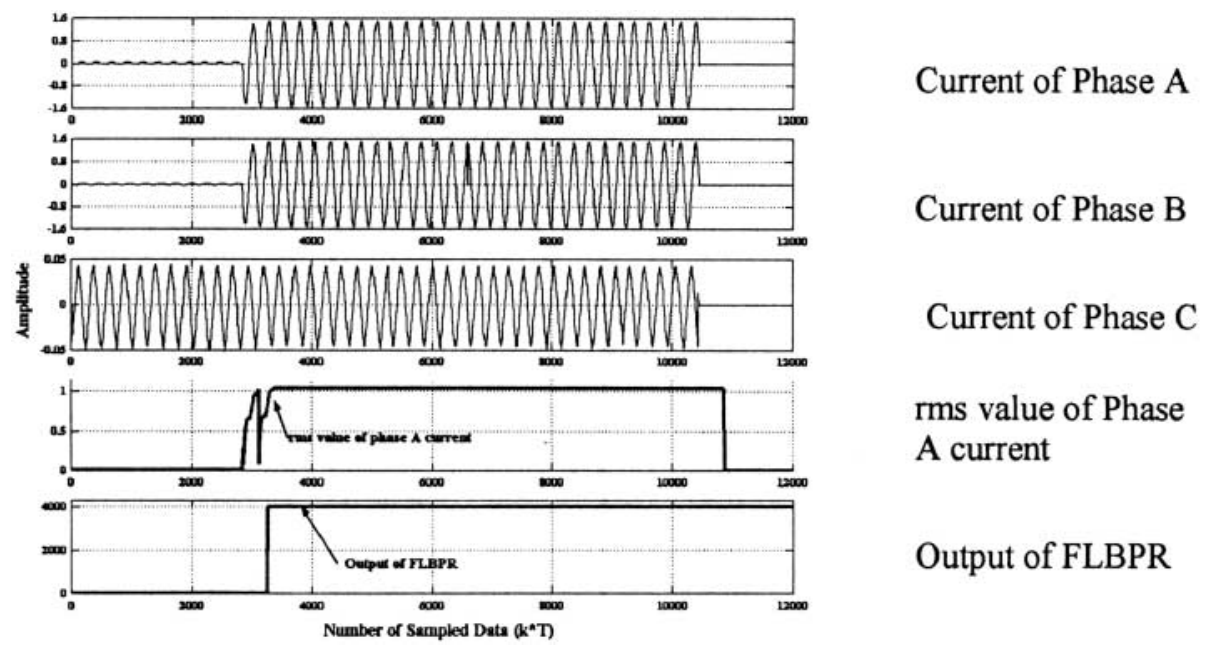

Figure 10. Double-phase fault between A and B and output of intelligent relay. 


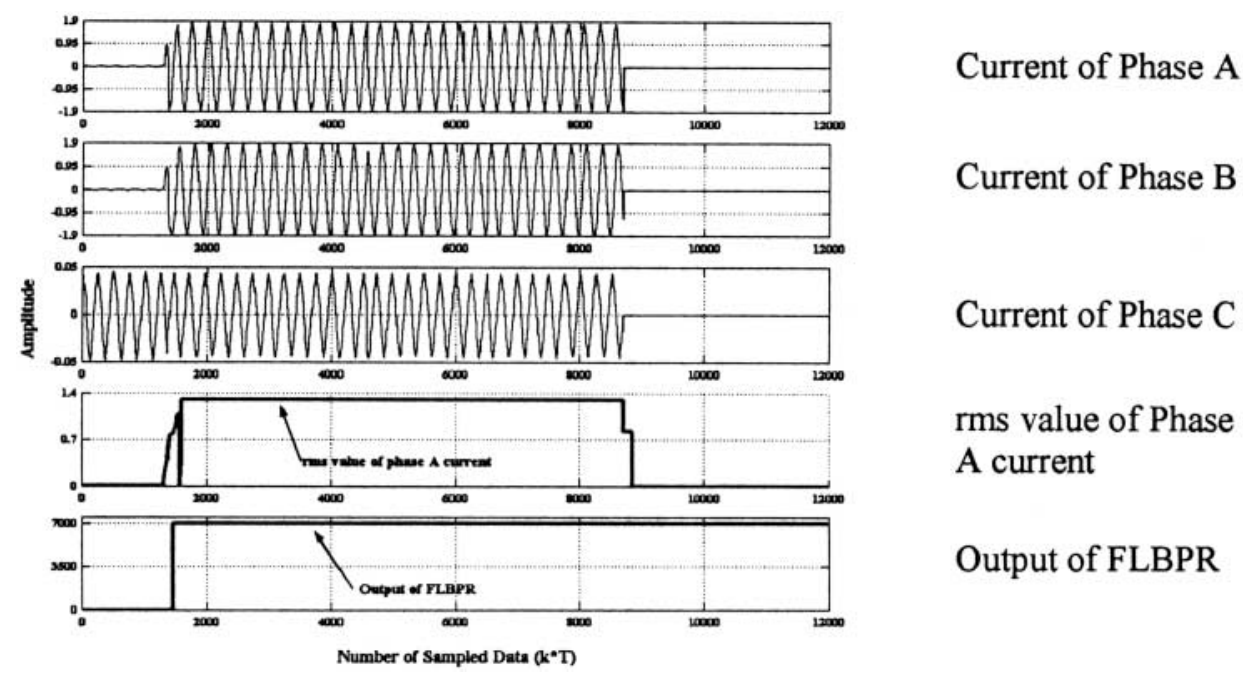

Figure 11. Double phase-neutral fault between A and B and intelligent relay output.

is increased from 1 to 4000, 5000, 6000, 7000, 8000, and 9000 for $\mathrm{A}-\mathrm{B}, \mathrm{B}-\mathrm{C}, \mathrm{A}-\mathrm{C}$, A-B-Neutral, B-C-Neutral, and A-C-Neutral faults, respectively. For the case of a three-phase fault, the output of the FLBPR is equal to 25,000 as shown in Fig. 12. Values of the FLBPR are selected arbitrarily and different outputs are observed for different faults.

Detection of fault type and faulty phases is a distinctive property for the proposed relay. In previous works related to distinguishing faulty phases and determination of fault type, the sampling rate is less than for the proposed relay. ${ }^{[21]}$ To determine whether the fault is transient or permanent, more time is required than for the proposed

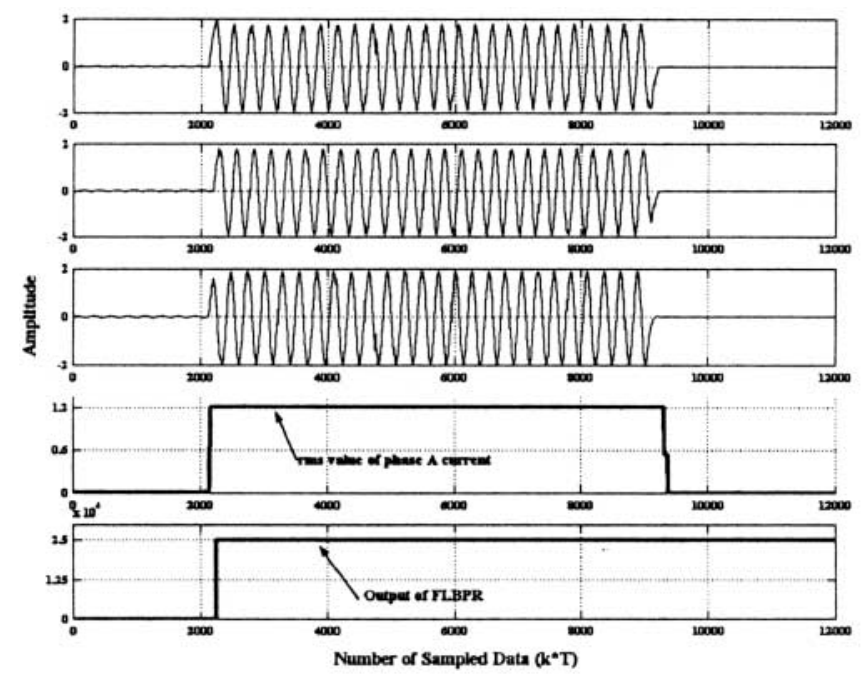

Current of Phase A

Current of Phase B

Current of Phase C

rms value of Phase

A current

Output of FLBPR

Figure 12. Balanced three phases fault and output of intelligent relay. 
relay. ${ }^{[20]}$ One of the FLBPR applications is reported by Ferrero et al. ${ }^{[22]}$ and eight rules are used. For the proposed relay, the number of rules is not sufficient to distinguish faulty phases and detection of single phase neutral and double phase faults. The duration of producing and sending of the control signal to the relay contact is about to $280 \mu \mathrm{sec}$ in the proposed relay. However, in previous works, this duration ranges from 2 to $40 \mathrm{msec}$. The proposed relay is applied to prototype power system protection, which is modeled from a real radial power system, and experiments are performed in real time. However, the presented results in the other proposed intelligent system based protective relays are obtained from simulation studies.

\section{CONCLUSIONS}

Fuzzy logic can be used to identify faults that may occur in a radial power system. Ten types of faults have been studied and considered for the proposed relay. The FLBPR model has no dependence on a mathematical model. A delay of 1-2 cycles in detection of faults when using rms values is expected, due to the algorithm required for determining the rms value. This may not be critical in practice. However, the FLBPR can be accomplished in practice using a micro-controller or integrated circuits. For this reason, the FLBPR is useful for hardware architecture. In addition, the measurement of the distance of the faulted point from the busbar and the dynamic behavior may be added to this relay in the future.

\section{REFERENCES}

1. D'Amore, D.; Ferrero, A. A simplified algorithm for digital distance protection based on Fourier techniques. IEEE Trans. Power Del. 1989, 4 (1), 157-164.

2. Girgis, A.A.; Makram, E.B. Applied of adaptive kalman filtering in fault classification, distance protection, and fault location using microprocessors. IEEE Trans. Power Syst. 1988, 3 (1), 301-309.

3. Balser, S.J.; Clements, K.A.; Lawrence, D.J. Microprocessor-based technique for detection of high-impedance faults. IEEE Trans. Power Del. 1986, PWRD-1 (3), 252-258.

4. Mansour, M.M.; Swift, G.W. Design and testing of a multi-microprocessor travelling wave relaying. IEEE Trans. Power Del. 1986, PWRD-1 (4), 74-81.

5. Damborg, M.J.; Ramaswami, R.; Jampala, A.K.; Venkata, S.S. Applied of relational to computer aided engineering of transmission protection systems. IEEE Trans. Power Syst. 1986, PWRS-1 (2), 187-193.

6. Phadke, A.G.; Ibrahim, M.; Hlibka, T. Fundamental basis for distance relaying with symmetrical components. IEEE Trans. Power Appl. Syst. 1977, PAS-96 (2), $635-642$.

7. Habib, M.; Martin, M.A. A comparative analysis of digital relaying algorithms for the differential protection of three phase transformer. IEEE Trans. Power Syst. 1988, 3 (3), 1378-1384.

8. Adamiak, M.G.; Jauch, J.P. Field experience with the AEP digital relay. IEEE Trans. Power Del. 1986, PWRD-1 (4), 91-98. 
9. Sachdev, M.S.; Aggarwal, R. A Technique for estimating transmission line fault locations from digital impedance relay measurements. IEEE Trans. Power Del. 1988, 3 (1), 121-129.

10. Lawrence, D.J.; Waser, D.L. Transmission line fault location using DFR. IEEE Trans. Power Del. 1988, 3 (2), 496-502.

11. Rahman, M.A.; Jeyasurya, B. A state-of-the-art review of transforfer protection algorithms. IEEE Trans. Power Del. 1988, 3 (2), 534-544.

12. Shebab-Eldin, E.H.; McLaren, P.G. Traveling wave distance protection-problem areas and solutions. IEEE Trans. Power Del. 1988, 3 (3), 894-901.

13. Dash, P.K.; Panda, D.K. Digital impedance protection of power transmission lines using a spectral observer. IEEE Trans. Power Del. 1988, 3 (1), 102-109.

14. Chihiro, F.; Kawakami, J. An expert system for fault section estimation using information from protective relays and circuit breakers. IEEE Trans. Power Del. 1986, $l$ (4), 83-91.

15. Horowits, S.H.; Phadke, A.G.; Thorp, J.S. Adaptive transmission system relaying. IEEE Trans. Power Del. 1988, 3 (4), 1436-1445.

16. Vuong, G.T.; Paris, G. Rule based relay modeling for transient stability studies. IEEE Trans. Power Syst. 1988, 3 (3), 1306-1309.

17. Girgis, A.A.; Johns, M.B. A hybrid expert system for faulted section identification, faults type classification, and selection of fault location algorithms. IEEE Trans. Power Del. 1989, 4 (2), 978-986.

18. Yongli, Z.; Yang, Y.H.; Hogg, B.W.; Zhang, W.Q.; Gao, S. An expert system for power systems fault analysis. IEEE Trans. Power Syst. 1994, 9 (1), 503-510.

19. Kim, C.J.; Russel, B.D. A Learning method for use in intelligent computer relays for high-impedance faults. IEEE Trans. Power Del. 1991, 6 (1), 109-115.

20. Kandil, N.; Sood, V.K.; Khorasani, K.; Patel, R.V. Fault identification in AC-DC transmission system using neural networks. IEEE Trans. Power Syst. 1992, 7 (2), 812-819.

21. Dalstein, T.; Kulicke, B. Neural network approach to fault classification for high speed protective relaying. IEEE Trans. Power Del. 1995, 10 (2), 1002-1011.

22. Ferrero, A.; Sangiovanni, S.; Zappitelli, E. A fuzzy-set approach to fault type identification in digital relaying. IEEE Trans. Power Del. 1995, 10 (1), 165-171.

23. El-Hawary, M.E. Electrical Power Systems: Design and Analysis; Reston Publishing Company Inc.: Reston, Virginia, 1983.

Received March 12, 2004

Accepted April 12, 2004

Manuscript 1434 